\title{
Prolonged-Release Capsule, Hard Dosage Form
}

National Cancer Institute

\section{Source}

National Cancer Institute. Prolonged-Release Capsule, Hard Dosage Form. NCI

Thesaurus. Code C149871.

Solid single-dose preparation consisting of a hard shell containing a solid or semi-solid formulation, showing a slower release of the active substance(s) than that of a conventional-release capsule. Prolonged release is achieved by a special formulation design and/or manufacturing method. Hard prolonged-release capsules are intended for oral use. 